\title{
Abnormalities of aortic arch shape after successful repair of aortic coarctation and systemic arterial hypertension
}

Roberto Crepaz

Pediatric Cardiology and Congenital Heart Disease in the Adult Dept. of Cardiology Regional Hospital S. Maurizio, Bolzano, Italy

Article Info

\section{Article Notes}

Received: November 27, 2017

Accepted: January 30, 2018

\section{${ }^{*}$ Correspondence:}

Dr. Roberto Crepaz

Pediatric Cardiology and Congenital Heart Disease in the

Adult Dept. of Cardiology Regional Hospital

S. Maurizio, Bolzano-Italy; E-Mail: robcrep@gmail.com;

(C) 2018 Crepaz R. This article is distributed under the terms of the Creative Commons Attribution 4.0 International License.
After successful repair of aortic coarctation (AoCo), many patients remain at risk for cardiovascular problems and major adverse prognostic factors have been identified ${ }^{1-4}$. After AoCo repair, different pathogenic mechanisms leading to persistent systemic arterial hypertension have been identified, including mild residual arch stenosis, increased aortic wall stiffness, hyperactivity of reninangiotensin system, impairment of the baroreflex system and peripheral vascular reactivity ${ }^{4}$.

An abnormal aortic arch shape has been associated with rest or exercise-induced arterial hypertension in the long-term follow-up of patients after repair of AoCo, without any residual arch obstruction ${ }^{3,5}$. Native aortic arch morphology, age at repair and surgical approach were all identified as possible causes for a persistent postoperative abnormal arch shape; however all these findings are still debated. An abnormal arch shape with either gothic or crenel morphology after surgical repair leads to an abnormal central aortic flow dynamic and increased aortic wall stiffness ${ }^{6}$, which can both contribute to the development of systemic arterial hypertension in the long-term ${ }^{7,8}$ (see Figure 1 and Figure 2).
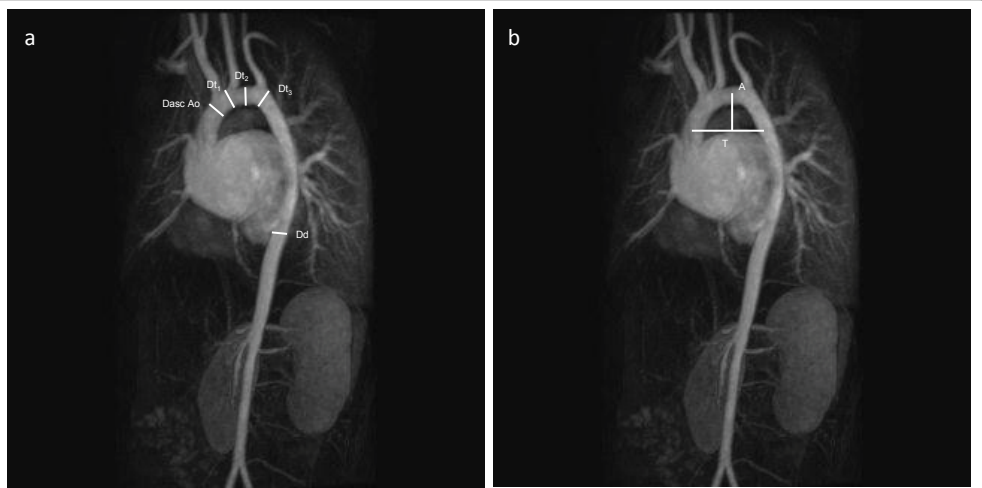

Figure 1. MR angiography of an aortic arch morphology in a patient following AoCo repair with normal arch shape.

Figure 1a. Dasc Ao: diameter of distal ascending aorta (before the brachiocephalic trunk); $\mathbf{D t}_{1}$ : diameter of proximal transverse arch (between brachiocephalic trunk and left carotid artery); $\mathbf{D t}_{2}$ : diameter of distal transverse arch (between left carotid artery and left subclavian artery); $\mathbf{D t}_{3}$ : diameter of the isthmus (after the left subclavian artery); Dd: diaphragmatic aorta diameter.

Figure 1b. T: maximal distance between the midpoints of the ascending and descending aorta, close to the axial plane going through the right pulmonary artery; A: maximal vertical distance between $T$ and the highest mid-point of the arch. 

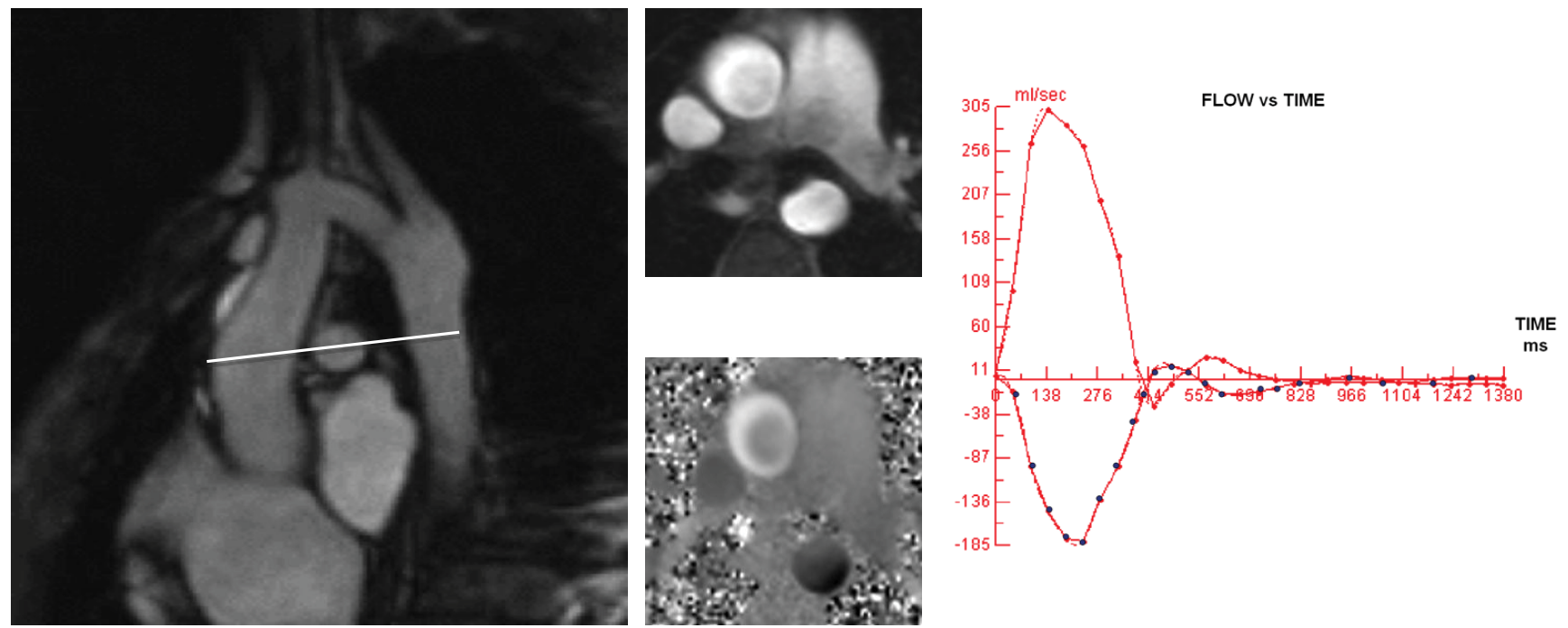

Figure 2. MR cine-sequence of an aortic arch morphology in a patient with gothic arch shape following AoCo repair.

Flow time curves of ascending (upper curve) and descending aorta (lower curve) obtained at the level of the white line. From these pictures we can estimate the distensibility of the ascending aorta and the percentage (\%) loss of systolic wave amplitude across the aortic arch (see Reference 13 for further details).

It has been widely shown ${ }^{2-5}$ that systemic hypertension is a major long-term complication after AoCo repair and moreover that patients with the gothic arch shape have a major risk to become hypertensive in the adult age. The ethiology of gothic arch shape is still not clear, with many controversial explanations. The gothic shape after AoCo repair is characterized by a greater aortic arch growth in height rather than in width. Ou et al. ${ }^{3}$ reported that patients with gothic shape were of an older age, suggesting that this anomaly could be acquired with age. There are also evidences that the type of surgical intervention could influence the prevalence of hypertension in long term. In particular, patients undergoing end-to-end anastomosis have a lower systolic blood pressure at follow-up than those undergoing subclavian flap repair or patch aortoplasty2,9,10. However other Authors report no significant differences in the prevalence of hypertension in relation to surgical repair techniques ${ }^{11,12}$.

According to published data $3,5,6,13$ a decreased ascending aorta distensibility coupled with an increased loss of systolic wave amplitude across the arch was reported in patients with a gothic shape after AoCo repair. The triangular-shaped morphology of the gothic arch could simply reflect the systolic wave inducing an early remodeling of the aortic wall. This is also confirmed by the evidence of morpho-functional alterations of the conduit arteries proximal to the AoCo repair site ${ }^{14-17}$, which are independent from time of intervention ${ }^{18-20}$. An increased resistance to pulsed wave propagation across the arch has been documented in the gothic arch shape group ${ }^{6}$. It has been also demonstrated that this arch shape abnormality leads in the long term to structural changes of the aortic wall and is responsible for an increased wall stiffness leading to exercise and rest hypertension together with left ventricular hypertrophy ${ }^{21,22}$.

In summary, a vascular remodeling develops after AoCo repair and could be faster in patients with gothic aortic arch shape. Aortic stiffness and increased left ventricular mass are both independent predictors of late morbidity and mortality in hypertensive patients ${ }^{23}$.

The gothic shape of the aortic arch, the reduced ascending aorta distensibility and the loss of systolic wave amplitude across the aortic arch, measured by MRI, correlate with systolic blood pressure and pulse pressure on ambulatory monitoring in a group of patients after successful AoCo repair ${ }^{13}$. An elevated pulse pressure is typical in elderly hypertensive patients and is due to a major vascular stiffness. As further confirmation of a prehypertensive state, subjects with a gothic arch shape show a higher day and night-time systolic blood pressure and a higher number of blood pressure measurements above the normal values for age ${ }^{13}$.

In conclusion, aortic wall remodeling is present in patients following AoCo repair. Those with a gothic arch shape may develop an earlier vascular stiffness and abnormal vascular hemodynamics, demonstrated also by a higher systolic blood pressure and pulse pressure on ambulatory monitoring and by exercise induced hypertension. These are all predisposing factors in developing arterial hypertension in the adult age.

We believe that all these observations highlight the need for a close follow-up of patients with gothic arch geometry after successful AoCo repair. The beneficial effects on outcome of pressure lowering treatment in subjects with increased central aortic stiffness are still under debate ${ }^{24}$. 
The identification of risk factors for hypertension associated with a gothic arch shape after AoCo repair might also helps to improve surgical strategies towards techniques aimed to obtain a more regular and smooth arch geometry at the time of the surgical repair.

\section{References}

1. Celermajer DS, Greaves K. Survivors of coarctation repair: fixed but not cured. Heart. 2002; 88: 113-114

2. O'Sullivan JJ, Derrick G, Darnell R. Prevalence of hypertension in children after early repair of coarctation of the aorta: a cohort study using casual and 24 hour blood pressure measurement. Heart. 2002; 88: $163-166$

3. Ou P, Bonnet D, Auriacombe L, et al. Late systemic hypertension and aortic arch geometry after successful repair of coarctation of the aorta. Eur Heart J. 2004; 25: 1853-1859

4. De Divitiis M, Rubba $\mathrm{P}$, Calabrò R. Arterial hypertension and cardiovascular prognosis after successful repair of aortic coarctation: a clinical model for the study of vascular function. Nutr Metab Cardiovasc Dis. 2005; 15: 384-392

5. Ou P, Mousseaux E, Celermajer DS, et al. Aortic arch shape deformation after coarctation surgery: effect on blood pressure response. J Thorac Cardiovasc Surg. 2006; 132: 1105-1111

6. Ou P, Celermajer DS, Raisky O, et al. Angular (Gothic) aortic arch leads to enhanced systolic wave reflection, central aortic stiffness, and increased left ventricular mass late after aortic coarctation repair: evaluation with magnetic resonance flow mapping. J Thorac Cardiovasc Surg. 2008; 135: 62-8.

7. Willum-Hansen T, Staessen JA, Torp-Pedersen C, et al. Prognostic value of aortic pulse wave velocity as index of arterial stiffness in the general population. Circulation. 2006; 113: 664-670

8. Dernellis J, Panaretou M. Aortic stiffness is an independent predictor of progression to hypertension in non hypertensive subjects. Hypertension. 2005; 45: 426-431

9. Kenny D, Polson JW, Martin RP, et al. Surgical approach for aortic coarctation influences arterial compliance and blood pressure control. Ann Thorac Surg. 2010; 90: 600-4

10. Walhout RJ, Lekkerkerker JC, Oron GH, et al. Comparison of polytetrafluoroethylene patch aortoplasty and end-to-end anastomosis for coarctation of the aorta. J Thorac Cardiovasc Surg. 2003; 126: 521-8

11. Seirafi PA, Warner KG, Geggel RL, et al. Repair of coarctation of the aorta during infancy minimizes the risk of late hypertension. Ann Thorac Surg. 1998; 66: 1378-82
12. Smith Maia MM, Cortês TM, Parga JR, et al. Evolutional aspects of children and adolescents with surgically corrected aortic coarctation: clinical, echocardiographic, and magnetic resonance image analysis of 113 patients. J Thorac Cardiovasc Surg. 2004; 127: 712-20

13. Donazzan L, Crepaz R, Stuefer J, et al. Abnormalities of aortic arch shape, central aortic flow dynamics and distensibility predispose to hypertension after successful repair of aortic coarctation. World J Pediatr Heart Surg. 2014; 5: 546-553

14. Ou P, Celermajer DS, Mousseaux E, et al. Vascular remodeling after successful repair of coarctation: impact of aortic arch geometry. J Am Coll Cardiol. 2007; 49: 883-890

15. Xu J, Shiota T, Omoto R, et al. Intravascular ultrasound assessment of regional aortic wall stiffness, distensibility and compliance in patients with coarctation of the aorta. Am Heart J. 1997; 134: 93-98

16. Brili S, Dernellis J, Aggeli C, et al. Aortic elastic properties in patients with repaired coarctation of aorta. Am J Cardiol. 1998; 82: 11401143

17. Vriend JW, de Groot E, de Waal TT, et al. Increased carotid and femoral intima-media thickness in patients after repair of aortic coarctation: influence of early repair. Am Heart J. 2006; 151: 242-247

18. De Divitiis M, Pilla C, Kattenhorn M, et al. Vascular dysfunction after repair of coarctation of the aorta: impact of early surgery. Circulation. 2001; 104 Suppl 1: I165-170

19. Vogt M, Kühn A, Baumgartner D, et al. Impaired elastic properties of the ascending aorta in newborns before and early after successful coarctation repair: proof of a systemic vascular disease of the pre stenotic arteries. Circulation. 2005; 111: 3269-3273

20. Meyer AA, Joharchi MS, Kundt G, et al. Predicting the risk of early atherosclerotic disease development in children after repair of aortic coarctation. Eur Heart J. 2005; 26: 617-22

21. O'Rourke M. Arterial stiffening and vascular/ventricular interaction. J Human Hypertens. 1994; 8(suppl): S9-15

22. London GM. Role of arterial wall properties in the pathogenesis of systolic hypertension. Am J Hypertens. 2005; 18(suppl): 19S-22S

23. Laurent S, Boutouyrie P, Asmar R, et al. Aortic stiffness is an independent predictor of all-cause and cardiovascular mortality in hypertensive patients. Hypertension. 2001; 37: 1236-1241

24. Williams B, Lacy PS, Thom SM, et al. CAFE Investigators; AngloScandinavian Cardiac Outcomes Trial Investigators; CAFE Steering Committee and Writing Committee. Differential impact of blood pressure-lowering drugs on central aortic pressure and clinical outcomes: principal results of the Conduit Artery Function Evaluation (CAFE) study. Circulation. 2006; 113: 1213-1225 